\title{
POLÍTICA CRIMINAL DO INIMIGO NO COMBATE À CRIMINALIDADE SEXUAL: NA CONTRAMÃO DAS EPISTEMOLOGIAS DO SUL
}

\author{
LA POLÍTICA CRIMINAL DEL ENEMIGO PARA LUCHAR CONTRA LA \\ DELINCUENCIA SEXUAL: DISCONFORME CON LAS EPISTEMOLOGÍAS DEL \\ SUR
}

\author{
${ }^{1}$ Silvia de Freitas Mendes \\ ${ }^{2}$ Dirceia Moreira
}

\section{RESUMO}

Este artigo visa problematizar a influência do discurso do direito penal do inimigo na política criminal brasileira relacionada aos crimes sexuais confrontando-o com o discurso das epistemologias do sul. Para tanto, foram apresentadas as premissas das epistemologias do sul, sua sociologia das ausências e a ecologia de saberes, bem como os fundamentos do direito penal do inimigo e as alterações político-criminais relativas aos crimes sexuais, entre os anos 2000 e 2015. O desenvolvimento destes objetivos deu-se a partir de pesquisa bibliográfica e quanto as alterações político-criminais relacionadas aos crimes sexuais, optou-se, enquanto método de trabalho, pela análise dos documentos legislativos.

Palavras-chave: Política criminal, Epistemologias do sul, Direito penal do inimigo

\section{RESUMEN}

Este artículo tiene como objetivo discutir la influencia del derecho penal del enemigo en la política criminal brasileña relacionada con delitos sexuales y el discurso de las epistemologías del sur. Así, presentamos los supuestos de estas, su sociología de las ausencias y la ecología de los saberes, los fundamentos del derecho penal del enemigo y los cambios político-penal relativos a los delitos sexuales, entre 2000 y 2015 . El desarrollo de estos objetivos se llevó a cabo a partir de la literatura y los cambios político-criminales relacionados con delitos sexuales, se elige como método, el análisis de los documentos legislativos.

Palabras-claves: Política criminal, Epistemologías del sur, Derecho penal del enemigo

\footnotetext{
${ }^{1}$ Doutoranda em Ciências Sociais Aplicadas na Universidade Estadual de Ponta Grossa - UEPG, Ponta Grossa - PR (Brasil). Professora da Universidade Estadual do Oeste do Paraná, UNIOESTE, Cascavel - PR (Brasil).

E-mail: silviamendes2005@yahoo.com.br

${ }^{2}$ Doutora em Direito pela Pontifícia Universidade Católica - PUC, São Paulo - SP (Brasil). Professora da Universidade Estadual de Ponta Grossa, UEPG, Ponta Grossa - PR (Brasil). E-mail: dirceiam@ gmail.com
} 


\section{INTRODUÇÃO}

O discurso fundamentado no medo e na insegurança ganha espaço e acaba por sustentar e possibilitar a criação e implementação de políticas criminais de cunho excessivamente punitivista. Exemplo disso é o chamado direito penal do inimigo, que tem como grande expoente Günther Jakobs. Neste modelo político-criminal, os direitos e garantias se veem ameaçados, instituindo-se guerra contra pessoas, sendo estas nem mesmo vistas como pessoas. (JAKOBS, 2007, p. 30)

Ocorre que é preciso repensar tal modelo político-criminal, não se pode sucumbir ao ponto de considerar cidadãos em não-pessoas assumindo uma postura extrema em termos de punição. Nesse sentido, torna-se necessário analisar as opções político-criminais adotadas pelo Estado brasileiro a fim de se tecer considerações e limites àquelas para se evitar, ou em não se evitando, trazer à tona as manifestações do direito penal do inimigo.

Neste artigo, propõe-se elaborar considerações críticas acerca da política criminal brasileira criada para se controlar a criminalidade sexual compreendida entre 2000 e 2015, período no qual ocorreram, principalmente com a lei 12015/09, alterações que demonstram um controle penal mais incisivo em relação as pessoas que praticam crimes sexuais. Para tanto, serão inicialmente apresentadas as epistemologias do sul, mais especificamente a sociologia das ausências e a ecologia de saberes propostas por Boaventura de Sousa Santos, com a finalidade de se propor uma forma de análise que prime por uma intervenção mínima do controle social penal e, em sendo necessária sua atuação, esteja pautada pela busca das ausências que permeiam a incansável bandeira de que vive-se de forma insegura e que o medo prevalece.

Após, será descrito a visão de Günther Jakobs sobre a função que atribui à pena, tendo em vista que, a partir da divisão que faz entre direito penal do cidadão e direito penal do inimigo, a pena é aplicada no primeiro caso. Também serão apresentadas a definição e caracterização do direito penal do inimigo, bem como alguns posicionamentos que criticam este modelo político- criminal.

Tais considerações teóricas contribuirão para análise da política criminal brasileira voltada aos crimes sexuais. Pretende-se, desse modo, identificar traços coincidentes entre o modelo político-criminal do inimigo na tratativa dos crimes sexuais no Brasil e além disso, tecer considerações acerca de uma possível influência da sociologia das ausências e 
ecologia de saberes nos momentos de criação e implementação das políticas criminais para se coibir a proliferação de políticas criminais que se transformem única e exclusivamente em forma de combate contra a pessoa humana. Para a elaboração dessa análise adotou-se a técnica de análise documental, sendo necessários tanto o levantamento de referencial teórico, quanto a verificação das leis ordinárias, consideradas as fontes documentais, que operaram alterações na política criminal voltada aos crimes sexuais entre os anos 2000 e 2015, permitindo uma análise desses diplomas legislativos a fim de se avaliar a expansão do controle social penal de cunho inimigo.

\section{EPISTEMOLOGIAS DO SUL GLOBAL: A SOCIOLOGIA DAS AUSÊNCIAS E ECOLOGia de SABERES COMO AUXílio a CONDUZIR A POLÍtica- CRIMINAL}

A produção do conhecimento científico perseguiu a pretensão de verdade absoluta desconsiderando a existência de outros conhecimentos. $\mathrm{O}$ enaltecimento do conhecimento científico pode receber crítica contundente a partir das epistemologias do sul global. Conforme Immanuel Wallerstein, referindo-se à ciência moderna, “Os cientistas pareciam afirmar que qualquer um poderia produzir conhecimento, desde que utilizasse os 'métodos' adequados (...)”. (2004, p. 125) Contrariamente, a matriz epistemológica do sul global desenvolvida por Boaventura de Sousa Santos, visa superar o pensamento abissal, no qual a visão epistemológica do norte global almeja o universalismo de suas teorias, excluindo o que entende ser irrelevante, desnecessário. Nesse sentido afirma SANTOS

\footnotetext{
O pensamento moderno ocidental é um pensamento abissal. Consiste num sistema de distinções visíveis e invisíveis, sendo que as invisíveis fundamentam as visíveis. As distinções invisíveis são estabelecidas através de linhas radicais que dividem a realidade social em dois universos distintos: o universo 'deste lado da linha' e o universo 'do outro lado da linha'. (2007, p. 03)
}

Esta divisão do mundo gerou impacto tanto no conhecimento como no direito. Quanto ao conhecimento, o pensamento abissal manifesta-se na exclusividade ou monopólio conferido à ciência moderna para determinar o que é verdadeiro e o falso. (SANTOS, 2007, p. 05) Exclui com isso, os conhecimentos ditos não-científicos, despreza o conhecimento que não tenha passado pelos rigores científicos. 
Já quanto ao direito moderno, a separação operada pelo pensamento abissal separa o legal do ilegal. Como decorrência desta dicotomia, tem-se que

\begin{abstract}
O legal e o ilegal são as duas únicas formas relevantes de existência perante a lei, e, por esta razão, a distinção entre ambos é uma distinção universal. Esta dicotomia central deixa de fora todo um território social onde ela seria impensável como princípio organizador, isto é, o território do a-legal, ou mesmo do legal e ilegal de acordo com direitos não oficialmente reconhecidos. (SANTOS, 2007, p. 06)
\end{abstract}

Diante disso, deve-se considerar a existência de diferentes formas de controle social e não apenas a via penal, tais como o educacional e da assistência social por exemplo. $\mathrm{O}$ controle social penal, sobrepõe-se com seu caráter punitivista, trazendo a pretensão de ser o controle necessário e imprescindível para a proteção de bens jurídicos, compreendendo-se estes como “(...) um elemento fundamental, que dota de conteúdo o tipo de ação, fazendo com que se possa pretender afirmar a ofensividade do fato em face do conjunto normativo (...)”. (BUSATO, 2013, p. 370) Isso faz com se promova a invisibilidade de outros saberes que podem contribuir para a proteção dos bens jurídicos. Conforme Sara Araújo, “A Norte ou a Sul, as sociedades sempre foram juridicamente plurais e palco de múltiplas instâncias de resolução de conflitos.” (2015, p. 30)

A partir desse panorama, pode-se apresentar a definição das epistemologias do sul global defendida por Boaventura de Sousa Santos. A matriz epistemológica do sul global corresponderia à

(...) valorização de conhecimentos válidos, científicos e não científicos, e de novas relações entre diferentes tipos de conhecimento, a partir das práticas das classes e grupos sociais que tem sofrido, de maneira sistemática, destruição, opressão e discriminação causadas pelo capitalismo, o colonialismo e todas as naturalizações da desigualdade nas quais se tem desdobrado; o valor de cambio, a propriedade individual da terra, o sacrifício da mãe terra, o racismo, o sexismo, o individualismo, o material acima do espiritual e todas as demais monoculturas da mente e da sociedade - econômicos, políticos e culturais - que tentam bloquear a imaginação emancipadora e sacrificar as alternativas. Neste sentido, são um conjunto de epistemologias, não apenas uma, que parte desta premissa, e de um Sul que não é geográfico, mas metafórico: o Sul anti-imperial. (2011, p. 16)

Portanto, as epistemologias do sul trazem à tona a existência de uma multiplicidade e possibilidades no campo do conhecimento, o qual não se resume ao conhecimento científico europeu com a pretensão universal. As epistemologias do sul global possuem três premissas para sua compreensão: inicialmente, deve-se entender que a compreensão de 
mundo é ampla e transcende a concepção ocidental de mundo. Também deve-se considerar que a diversidade do mundo é infinita. E, finalmente, que tal diversidade “(...) que pode ser e deve ser ativada, assim transformada teoricamente e na prática de muitas maneiras plurais, não pode ser monopolizada por uma teoria geral.” (SANTOS, 2011, p. 16-17)

Além disso, SANTOS estabelece o trabalho das epistemologias do sul. Afirma que existem histórias para além da história do Ocidente. Desse modo, o trabalho das epistemologias do sul consiste em estudar, analisar as outras histórias, trazê-las à tona. Boaventura de Sousa Santos propõe três procedimentos para desenvolver o mencionado trabalho: a sociologia das ausências (partindo da noção de que o presente é um passado incompleto), a sociologia das emergências (parte do futuro como presente não cumprido) (SANTOS, 2011, p. 17) e o trabalho de tradução como meio complementar aos dois procedimentos (SANTOS, 2002, p. 267) No presente artigo será abordado o procedimento da sociologia das ausências, valendo-se da ecologia de saberes, para análise da influência do modelo político-criminal do inimigo na política criminal brasileira relativa aos crimes sexuais.

Antes de se especificar o procedimento da sociologia das ausências, é necessário mencionar que SANTOS a propõe como forma de combate a chamada razão metonímica. Esta razão é caracterizada pela obsessão da ideia de totalidade vinculada à ordem. Para a razão metonímica, "Não há compreensão nem acção que não seja referida a um todo e o todo tem absoluta primazia sobre cada uma das partes que o compõem.” (SANTOS, 2004, p. 782)

Esta razão metonímica produziria duas consequências principais. A primeira delas seria a desconsideração de tudo que estiver fora da totalidade, portanto sendo inexistente, descartável. E como segunda consequência, nenhuma das partes pode ser pensada ou analisada sem considerar a totalidade. (SANTOS, 2004, p. 782-783) Verifica-se que a razão metonímica organiza um mundo da inexistência ao desprezar o que não segue a sua racionalidade ocidental. As especificidades da realidade social podem ser descartadas em prol do prevalecimento da totalidade.

Nesse contexto, a sociologia das ausências visa resgatar “(...) a experiência desperdiçada." (SANTOS, 2004, p. 785) E é definida como uma forma de investigação, a qual tem como finalidade “(...) demonstrar que o que não existe é, na verdade, 
activamente produzido como tal, isto é, como uma alternativa não-credível ao que existe.” (SANTOS, 2002,

p. 246)

A sociologia das ausências impulsiona o rompimento do pensamento abissal. SANTOS propõe um pensamento pós-abissal, o qual seria “(...) um aprender com o Sul usando uma epistemologia do Sul. Confronta a monocultura da ciência moderna com uma ecologia de saberes." (SANTOS, 2007, p. 22) Esta ecologia de saberes propugna a existência de múltiplos saberes, sendo a ciência moderna apenas um deles.

O pensamento pós-abissal tem como condição o reconhecimento da co-presença radical. Esta considera que as práticas e os agentes pertencentes aos dois lados da linha coexistem igualmente. Nesse sentido,

Todos os conhecimentos sustentam práticas e constituem sujeitos. Todos os conhecimentos são testemunhais porque o conhecem sobre o real (a sua dimensão activa) se reflecte sempre no que dão a conhecer sobre o sujeito do conhecimento (a sua dimensão subjectiva). (...) A ecologia de saberes expande o carácter testemunhal dos conhecimentos de forma a abarcar igualmente as relações entre o conhecimento científico e não-científico, alargando deste modo o alcance da inter-subjetividade como interconhecimento e vice-versa. (SANTOS, 2007, p. 27)

A análise da produção do conhecimento influencia e provém de práticas, e com isso denota-se a inviabilidade de se considerar apenas o conhecimento científico ou prevalecimento de apenas um conhecimento científico com pretensão de verdade absoluta como fonte do conhecimento. A ecologia de saberes exige uma reavaliação das intervenções e relações no meio social, porém, não se esquece da hierarquia entre saberes, “(...) Contudo, em lugar de subscrever uma hierarquia única, universal e abstracta entre os saberes, a ecologia de saberes favorece hierarquias dependentes do contexto, à luz dos resultados concretos pretendidos ou atingidos pelas diferentes forma de saber. (SANTOS, 2007, p. 27)

Além disso, por força da adoção da ecologia de saberes, deve-se levar em conta os princípios da precaução e incompletude. Em relação ao primeiro, a primazia será de formas de conhecimento que viabilizem a maior participação de grupos sociais “(...) envolvidos na concepção, na execução, no controlo e na fruição da intervenção.” (SANTOS, 2007, p. 29) Já do princípio da incompletude decorre o diálogo e disputa entre os diferentes saberes. 
"O que cada saber contribui para esse diálogo é o modo como orienta uma dada prática na superação de uma certa ignorância." (SANTOS, 2002, p. 250)

A partir dessas considerações acerca das epistemologias do sul e, de forma mais detida, em relação à sociologia das ausências e a ecologia de saberes, pode-se pensar a construção de políticas criminais que primem pela compreensão de que o direito não deve ser a única via de solução para os problemas sociais, nem mesmo o discurso com pretensão de se constituir no saber mais importante. A política criminal que possa promover o fundamento constitucional da dignidade da pessoa humana, deverá passar pela ecologia de saberes.

Nesse sentido, a consideração da existência de múltiplos saberes, bem como da observância dos princípios da incompletude e precaução devem contribuir para a análise da intervenção penal como controle social. Portanto, seria possível visualizar um limite à expansão penal e da excessiva punição ou estigmatização de pessoas.

\section{POLÍTICA CRIMINAL DO INIMIGO: SEM PRECAUÇÃO E COM PRETENSÃO DE COMPLETUDE}

Sob o discurso de reduzir criminalidade, com a promessa de se conferir mais segurança, pode-se verificar o surgimento de tendências político-criminais de cunho extremamente punitivista, as quais não primam pela arguição das ausências nem mesmo pela ecologia de saberes, postulados das epistemologias do sul global, para se analisar a necessidade ou não intervenção penal. Dentre tais vertentes, tem-se o chamado direito penal do inimigo, que tem como seu expoente Günther Jakobs. Para se compreender a teorização do direito penal do inimigo proposta por Jakobs, será apresentada primeiramente sua perspectiva a respeito das funções da pena, haja vista que esta será objeto de análise no próprio modelo político-criminal mencionado.

Günther Jakobs é um dos grandes defensores da prevenção geral positiva como função da pena. Defende que as pessoas vivem em um mundo já conformado, no qual existem normas estáveis, as quais não podem ser desrespeitadas. Dessa forma, 
Uma decepção específica no âmbito dos contatos sociais afeta aquelas expectativas que derivam da pretensão frente à outra parte de que serão respeitadas as normas vigentes, podendo a pretensão contradizer ao juízo cognitivo. Exemplo: Tampouco quem vê como o condutor bebe renuncia a sua pretensão a uma viagem segura. A uma expectativa normativa não se tem de renunciar nem sequer em casos de decepção, somente que esta pode manter-se (contrafaticamente), se como falha decisiva não se define a expectativa do decepcionado, somente a infração da norma por parte daquele que a decepciona. (JAKOBS, 1997, p. 10, tradução nossa)

Com isso, Jakobs pretende conferir importância considerável à norma, como centro de proteção do direito penal. Para garantir a estabilização da norma, seria necessário a pena. Conforme o mencionado autor:

\begin{abstract}
Somente a expectativa consistente no fato de que quem participa no contato social vai querer respeitar as normas não torna planejados tais contatos, já que a outra parte não somente deve ter a boa vontade de respeitar a ordem, mas deve também saber quando está diante de um comportamento normativamente regulado. Exemplo: Quem não quer pôr em perigo os outros, somente pode comportarse não perigosamente se sabe quais comportamentos são perigosos. (JAKOBS, 1997, p. 11, tradução nossa)
\end{abstract}

Diante disso, a partir do momento em que se violasse alguma dessas normas, o que desestabilizaria o sistema normativo, ao transgressor seria aplicada uma pena. Exigese, portanto, que o autor atue conforme a norma. Assim:

a contradição à norma por meio de uma conduta é a infração da norma. Uma infração normativa é, portanto, uma desautorização da norma. Esta desautorização dá lugar a um conflito social na medida em que se põe em evidência a norma como modelo de orientação. (JAKOBS, 1997, p. 13, tradução nossa)

Como se vê, a realização de uma conduta contrária à norma ensejaria a aplicação de pena para se manter a estabilização do sistema normativo. Diante disso, a pena seria uma

reação frente a infração de uma norma. Mediante a reação sempre se põe de manifesto que tenha de observar-se a norma. E a reação demonstrativa sempre tem lugar a custa doresponsável pela infração da norma (por 'a custa de' se entende, neste contexto, a perda de qualquer bem). (JAKOBS, 1997, p. 08, tradução nossa)

O posicionamento de Jakobs sobre a prevenção geral positiva pretende preservar a estabilização do sistema normativo. Ocorre que, ao se adotar tal perspectiva, acaba-se por se preterir a proteção de bens jurídicos. Nesse sentido, 
no aspecto fundamental para um Direito Penal garantista, resulta que se desatende ao objeto de proteção jurídico-penal, qual seja, o bem jurídico. Castiga-se, então, pelo fato de o autor do delito rebelar-se contra a norma em vez de produzir a ofensa a um bem jurídico. (BUSATO; MONTES HUAPAYA, 2003, p. 204)

Desse modo, privilegiar a norma implica em sonegar proteção ao próprio cidadão, dado que, em muitos casos, é o titular do bem jurídico. Além do mais, em Estados Democráticos de Direito, deve prevalecer a proteção de bens jurídicos, já que nestes Estados são estabelecidos um rol de direitos e garantias do qual é destinatário o indivíduo e não a norma. Conforme Mir Puig "Basear a teoria jurídica no reconhecimento de que o Direito deve servir ao cidadão me parece imprescindível para uma concepção democrática de Direito.” (MIR PUIG, 2006, p. 335, tradução nossa)

Como o indivíduo é detentor de direitos e garantias, não há possibilidade de se aceitar a concepção de Jakobs, tendo em vista a eliminação de garantias para se alcançar a estabilização da norma. Acreditar que a pena privativa de liberdade visa proteger a norma estar-se-ia dando azo ao surgimento de um "neoretribucionismo, que elimina de seu ideário aqueles únicos aspectos 'garantistas' ínsitos ao retribucionismo clássico, o chamado princípio de proporcionalidade”. (QUINTERO OLIVARES, MORALES PRATS, PRATS CANUT, 1997, p. 88, trad. nossa.)

Essa importância conferida à norma conforme a concepção de Jakobs, ganha grandes proporções em decorrência da necessária contenção para que o sistema normativo não seja ofendido, desestabilizado e acaba por impulsionar a distinção que o autor faz entre um direito penal do cidadão e o direito penal do inimigo. Günther Jakobs, ao explicar a existência do modelo político-criminal do inimigo, parte das concepções de Thomas Hobbes e Inmanuel Kant sobre a existência de cidadãos e inimigos do Estado. (JAKOBS, 2007, p. 27)

Acerca das suas fundamentações teóricas, Jakobs menciona a perspectiva de Hobbes, na qual deveria ser observada a distinção entre o súdito e o inimigo do Estado. Este caracterizava-se pela negativa ao disposto no pacto social, recusando-se mediante a prática de atos ou palavras a reconhecer a autoridade do representante do Estado. Desse modo, contra o inimigo seria autorizada a prática de quaisquer atos hostis que resultassem em quaisquer danos. (HOBBES, 2007, p. 230) Com isso, não seriam aplicadas penas aos inimigos, "Posto que esse inimigo nunca esteve sujeito à lei e não pode transgredila. Ou esteve sujeito a ela e professa não mais o estar (...).” (HOBBES, 2007, p. 229-230) 
Já em relação as influências de Kant na construção teórica do direito penal do inimigo de Jakobs, verifica-se que àquele que não quer se submeter às regras previstas na Constituição de um Estado, poderá se proceder de modo hostil. (JAKOBS, 2007, p. 28) Nesse sentido, afirma JAKOBS,

\begin{abstract}
Como acaba de citar-se, na posição de Kant não se trata como pessoa quem «me ameaça...constantemente», quem não se deixa obrigar a entrar em um estado cidadão. De maneira similar, Hobbes despersonaliza o réu de alta traição: pois também este nega, por princípio, a constituição existente. Por conseguinte, Hobbes e Kant conhecem um Direito penal do cidadão - contra pessoas que não delinquem de modo persistente por princípio e um Direito penal do inimigo contra quem se desvia por princípio. (2007, p. 29)
\end{abstract}

Ao considerar essa distinção entre cidadãos e inimigos do Estado, surge dois direitos penais. Jakobs propõe a distinção entre pessoas que apenas delinquem, que cometem erros, sendo-lhes aplicada determinada pena, cumprindo sua função estabilizadora do sistema normativo; daqueles denominados inimigos, definidos como indivíduos que se comportam de maneira duradoura a infringir a segurança das pessoas ou que reincidam persistentemente, portanto que se propõe a, permanentemente, desestabilizar o sistema normativo. (JAKOBS,

2007, p. 42 e 29) Assim, para cumprir a função preventivo geral de estabilização do sistema normativo, tanto no direito penal do cidadão como no direito penal do inimigo, se levaria às últimas consequências a proteção de tal sistema.

De acordo com esse modelo político-criminal, conforme Jakobs, podem ser considerados como exemplos de inimigos do Estado os terroristas, aqueles que façam parte da chamada criminalidade organizada, os autores de delitos sexuais e de infrações penais perigosas. (JAKOBS, 2007, p. 34) A estes não seria aplicado o direito penal do cidadão, o qual “(...) é o Direito de todos, o Direito penal do inimigo é daqueles que o constituem contra o inimigo: frente ao inimigo, é só coação física, até chegar à guerra." (JAKOBS, 2007, p. 30)

E ainda, de acordo com Cancio Meliá

A essência deste conceito de Direito penal do inimigo está, então, em que constitui uma reação de combate, do ordenamento jurídico, contra indivíduos especialmente perigosos, que nada significam, já que de modo paralelo às medidas de segurança, supõe tão-só um processamento desapaixonado, instrumental, de determinadas fontes de perigo, especialmente significativas. Com este instrumento, o Estado não fala com seus cidadãos, mas ameaça seus inimigos. (2007, p. 70-71) 
A partir das considerações de Jakobs e de Cancio Meliá, percebe-se que o punitivismo pode ser levado ao extremo, fazendo com que desapareçam direitos e garantias daqueles que também são pessoas, porém rotuladas como inimigas do Estado, inclusive com a despersonalização de grupos étnicos. Tal concepção político-criminal gera consequências que implicarão no expansionismo do direito penal material, bem como nas regras de natureza processual penal. Conforme MUÑOZ CONDE, o Direito penal do inimigo pode ser associado ao chamado direito penal de autor,

\footnotetext{
A primeira observação que se pode fazer a JAKOBS é que seu 'Direito penal do inimigo recorda muito o 'Direito penal de autor' que propugnaram os penalistas nazistas, segundo o qual o relevante não era o fato delitivo cometido, mas sim a 'perversão', 'inclinação ou tendência ao delito' ou periculosidade criminal que pudesse ter o autor. (2005, p. 37)
}

Diante dessas exemplificações, resta claro que o direito penal do inimigo acaba por consistir em resposta ultraviolenta, considerando como um de seus inimigos aquele que insiste na prática delitiva. Esta concepção não estabelece limites para se considerar quem seja esse inimigo. Fala em rompimento com o contrato social, traz alguns exemplos como as condutas dos terroristas e delinquentes sexuais, porém há que se compreender que uma vez criada a concepção teórica, esta gera impactos diante de sua adoção para conduzir a criação e implementação de políticas criminais. Isso pode gerar como consequências, a definição e estigmatização de pessoas como não-pessoas por mero capricho de detentores do poder ou por critérios de cunho subjetivos para fins de punição. Conduzirá a transformação da legislação penal e processual penal eminentemente punitiva ou, como afirma o próprio professor Jakobs, objetivando a guerra contra inimigos. Inimigos que, por mais que a referida concepção insista em não os considerar como pessoas, são pessoas.

E esta transformação de pessoas em inimigos vem respaldando, em muitas situações, ganhando espaço com base no discurso do medo e do risco. Conforme Paulo César Busato,

O discurso que aparece então é o da necessidade absoluta de segurança, que faz justificar um tratamento diferenciado e recrudescente ao delinquente, convertendo o modelo de controle social do intolerável em um modelo intolerável de controle social, transformando-se de um Direito penal do risco em um Direito penal do inimigo. E, no afã de alcançar este objetivo inatingível de paladino do controle da violência, o Direito penal 'tem deixado cair a bagagem democrática, a qual é um obstáculo na realização das novas tarefas'. (2007, on line) 
Esse discurso da imprescindibilidade de segurança, a propagação da existência de muitos riscos aos bens jurídicos sustenta a existência do direito penal do inimigo, referenda o que Jakobs denomina de legítima defesa do Estado. Nesse sentido afirma o autor,

Denomina-se 'Direito' o vínculo entre pessoas que são titulares de direitos e deveres, ao passo que a relação com um inimigo não se determina pelo Direito, mas pela coação. No entanto, todo Direito se encontra vinculado à autorização para empregar coação, e a coação mais intensa é o Direito penal. Em consequência, poder-se-ia argumentar, que qualquer pena, ou, inclusive, qualquer legítima defesa se dirige contra um inimigo. (2007, p. 25)

A legítima defesa ganha uma conotação mais agressiva no modelo políticocriminal do inimigo. Autoriza o Estado a promover atrocidades contra os chamados inimigos. Isso é identificável tendo em vista que em outra passagem já citada JAKOBS defende ser possível chegar à guerra contra o inimigo. Dessa forma, a legítima defesa poderá restar afastada da existência de seus requisitos de proporcionalidade e uso de meios necessários. A expansão do controle social penal neste caso resta evidente.

Essa reação contra o inimigo permite a identificação de algumas características do direito penal do inimigo. MORAES aponta alguns exemplos: a tipificação de atos meramente preparatórios, de crimes de mera conduta e de perigo abstrato; penas desproporcionais; legitimação do discurso de guerra contra o crime; restrição de direitos e garantias. (2006, p. 168)

Em relação à tipificação de atos meramente preparatórios, tal postura implica no adiantamento das barreiras de imputação, o que enseja a expansão penal. Em decorrência desse adiantamento, aumenta-se os atos meramente preparatórios descritos como crimes na legislação. Fere-se, novamente, a organização da teoria geral do delito, pois sabese que a regra é que sejam punidas a prática de atos de execução, seja na modalidade tentada ou consumada.

Não apenas este adiantamento das barreiras de imputação, como também o aumento das penas atribuídas a condutas já tipificadas exteriorizam a política criminal do inimigo. Esse modelo político-criminal do inimigo acaba por infringir direitos e garantias haja vista que uma de suas características é travar uma guerra contra o inimigo. 


\section{CAMINHO POLÍTICO-CRIMINAL BRASILEIRO RELATIVO AOS CRIMES SEXUAIS: DO INIMIGO OU PRÓ- EPISTEMOLOGIAS DO SUL?}

A partir das considerações acerca das epistemologias do sul e do que fundamenta e caracteriza o direito penal do inimigo, torna-se possível tecer considerações acerca de um provável distanciamento entre o que propõe a matriz epistemológica e o modelo político- criminal mencionados ao se analisar o percurso relativo à criação e alteração dos crimes sexuais no período compreendido entre os anos 2000 e 2015. Este modelo de política criminal possui traços que demonstram o predomínio colonial da cultura punitivista do norte, bem como afasta de forma gritante a multiplicidade de saberes. Primeiramente, será analisada a legislação penal relacionada aos crimes sexuais e suas alterações, para num segundo momento traçar as considerações acerca dos parâmetros teóricos eleitos para construção deste artigo.

Os crimes sexuais, tipificados no Código Penal brasileiro entre os artigos 213 ao 234, sofreram alteração considerável, principalmente com o advento da lei 12015/09 e alterações operadas na lei de crimes hediondos, lei 8072/90 (BRASIL, 1990). Porém, antes da lei 12015/09, já havia ocorrido algumas alterações em certas tipificações no título VI do Código Penal. Estas alterações foram estabelecidas pelas leis 10224/01 e 11106/05.

Em decorrência da lei 10224/01, houve a inclusão do artigo 216-A, segundo o qual pune-se o assédio sexual com penas de detenção de um a dois anos. (BRASIL, 2001) Este artigo foi alterado pela lei 12015/09, possibilitando um aumento de até um terço, caso a vítima tenha idade inferior a dezoito anos. (BRASIL, 2009)

Já a lei 11106/05, retirou a expressão mulher honesta, substituindo-a pelo termo alguém no tipo penal intitulado como posse sexual mediante fraude (artigo 215) e aumentou a pena para dois a seis anos. (BRASIL, 2005) Apesar disso, a lei 12015/09, reescreve a conduta prevista no artigo 215, nomina-o como violência sexual mediante fraude, ampliando a abrangência da conduta, mantendo-se a pena, mas inserindo no seu parágrafo único a possibilidade, se a prática tiver como finalidade obter vantagem econômica, também a aplicação da pena de multa. (BRASIL, 2009)

Apesar dessas alterações, a lei 12015/09 gerou maiores impactos nos crimes sexuais. Uma série de modificações foram realizadas ampliando a incidência do controle penal ou possibilitando seu exercício com maior rigor. Já no início, altera-se o artigo 213, 
incorporando as condutas que anteriormente estavam inseridas no artigo 214, que previa o atentado violento ao pudor. Manteve-se a pena de seis a dez anos, mas em seus parágrafos percebe-se os aumentos da pena quanto resultar lesão grave ou a vítima tiver idade inferior a dezoito anos e superior a quatorze, prevendo-se pena de oito a doze anos. E na hipótese de produzir o resultado morte, a pena varia entre doze a trinta anos. (BRASIL, 2009)

Em relação ao 217-A, estupro de vulnerável, foi inserido pela lei 12015/09 com penas que entre oito a quinze anos. Em seus parágrafos verifica-se a existência de penas mais altas se ocorrer o resultado lesão grave - pena de dez a vinte anos de reclusão - e se provier o resultado morte - reclusão de doze a trinta anos. (BRASIL, 2009)

A lei 12015/09 também aumentou as penas do tipo penal previsto no artigo 218. As penas variavam entre os limites de um a quatro anos de reclusão e passaram a reclusão de dois a cinco anos. Além disso, inseriu nova conduta prevista no artigo 218-A, intitulado como satisfação de lascívia mediante a presença de criança ou adolescente, com penas de reclusão de dois a quatro anos, bem como o artigo 218-B. Este prevê penas de reclusão entre quatro a dez anos para o chamado favorecimento da prostituição ou de outra forma de exploração sexual de criança ou adolescente ou de vulnerável. São punidos com as mesmas penas previstas no artigo 218-B, aqueles que mantém conjunção carnal ou outro ato libidinoso com pessoas menor de dezoito anos e maior de quatorze e aqueles que sejam proprietários, gerentes ou responsáveis pelo local onde haja o favorecimento à prostituição. (BRASIL, 2009)

Outro ponto a mencionar que respeita às alterações relacionadas ao crime de estupro especificamente, é ser, já a partir de 1994, considerado como crime hediondo. Como a análise proposta neste trabalho compreende o período entre os anos 2000 e 2015, importa relatar que no ano de 2007 a lei 11464 alterou a lei dos crimes hediondos (8072/90). (BRASIL, 2007) Com essas alterações, também há um controle penal mais incisivo quanto ao crime de estupro (além dos demais crimes hediondos e equiparados), tendo em vista que se impossibilitou a concessão de fiança, dificultou-se a progressão de regimes aumentando para dois quintos para os denominados primários e três quintos para os reincidentes. Também se aumentou o prazo para a prisão temporária para trinta dias. (BRASIL, 2007)

Percebe-se, através dessas alterações, que são traçadas linhas abissais para reafirmar a existência de um direito penal mais agressivo contra aqueles que praticam crimes de 
natureza sexual, travando um verdadeiro combate e não se investindo em outras formas de controle em relação a esse tipo de criminalidade.

A inserção do estupro de vulnerável - artigo 217-A do Código penal - na lei dos crimes hediondos se deu com a lei 12015/09. E, posteriormente, com a lei 12978/14 o favorecimento da prostituição ou de outra forma de exploração sexual de criança ou adolescente ou de vulnerável, previsto no artigo 218-B do Código penal, também fora inserido na lei 8072/90. (BRASIL, 2014)

Outro exemplo que demonstra a equiparação dos autores de crimes sexuais como inimigos do Estado, é o artigo $9^{\circ}$-A da lei 12654/12. Conforme este dispositivo, todos os condenados pela prática do crime de estupro e estupro de vulnerável, porque já classificados como crimes de natureza hedionda, estarão sujeitos à extração de DNA para identificação do seu perfil genético a ser mantido em banco de dados sigiloso. (BRASIL, 2012) Essa medida estigmatiza esse grupo de condenados, já que o Estado pressupõe que futuras práticas delitivas possam ser cometidas por parte dos mesmos. Não se propõe como medida estatal a utilização de outros saberes, como os da psicologia ou da assistência social, para se promover a dignidade destes condenados, opta-se por se valer ainda mais do controle social penal.

Diante dessa análise dos diplomas legislativos, o qual inseriram ou alteraram a política criminal relacionada aos crimes sexuais, é possível tecer considerações sobre o possível distanciamento das epistemologias do sul, especificamente da sua sociologia das ausências e ecologia de saberes, e de uma aproximação com o direito penal do inimigo.

À luz das epistemologias do sul deve-se primar por se perquirir o que está oculto, trazendo as ausências à tona, compreendendo-se que pode existir uma gama de possibilidades, visões acerca de uma mesma situação. No que respeita à política criminal brasileira compreendida entre os anos 2000 e 2015 voltada aos crimes sexuais, percebe-se uma preocupação em se ampliar o controle social penal, afastando-se uma perspectiva de acordo com a ecologia de saberes. Esta perspectiva se afastada pela desconsideração de outros saberes que contribuam no exercício do controle social frente a prática de violações à dignidade sexual. A política criminal brasileira reforçou o discurso de guerra àqueles que praticam crimes sexuais, não se valendo de outros saberes a fim de se questionar os motivos que levam à prática ou a possibilidade de se dar um atendimento diferenciado a estas pessoas. 
Vale-se do controle social penal, ampliou-se as condutas e penas com as alterações legislativas. Isso faz com que se perceba traços de uma política criminal do inimigo ao invés de incentivar a construção de políticas criminais com fundamento na sociologia das ausências e ecologia de saberes.

Em nenhuma das leis que alteraram o Código penal e a lei de crimes hediondos referidas neste artigo, consta quaisquer menções a proposições que envolvam outros saberes. Percebe-se a manifestação da razão metonímica, transformando em inexistentes as demais possibilidades de controle social, bem como formas mais eficazes de políticas públicas.

\section{CONSIDERAÇÕES}

No modelo da política criminal do inimigo nota-se o prevalecimento do direito como a única forma viável e correta de se controlar a criminalidade. Exalta, assim, o paradigma epistemológico punitivista do norte global, com pretensão de verdade e exclusividade.

Dessa forma, afasta a alternativa de aplicação das premissas das epistemologias do sul, bem como do instrumento da sociologia das ausências e da ecologia de saberes para a criação e implementação das políticas criminais. A utilização destas como filtro para as políticas criminais contribuiria para limitar a expansão do direito penal do inimigo e de qualquer excesso em relação à pena.

A sociologia das ausências e a ecologia de saberes permitiriam frear o discurso de guerra contra os inimigos, afastando-se a transformação de pessoas em não-pessoas como pretende Günther Jakobs. Outrossim, ensejariam uma nova abordagem da política criminal voltada aos crimes sexuais.

Nota-se, contrariamente às epistemologias do sul, a política criminal brasileira compreendida entre os anos de 2000 e 2015 no que tange aos crimes sexuais, caracterizase com a pretensão de completude, transformando-se em instrumento de combate contra aqueles que praticaram tais crimes, conferindo-se ao direito penal como ramo do saber um prevalecimento sem confronto com outros saberes, outras possibilidades. Não se observa o princípio da precaução, pois em decorrência deste a política criminal deveria possibilitar a maior participação possível de grupos sociais. Isso ensejaria discussões amplas e análise acerca da viabilidade do controle que se pretenda exerce. Com isso, percebe-se uma 
aproximação da política criminal ora discutida muito mais com o viés punitivista, sob o discurso do combate, proposto pelo direito penal do inimigo, aumentando-se penas, alterando-se a lei de crimes hediondos impedindo-se a concessão de certos institutos penais e também de interferências na execução da pena, estigmatizando pessoas como inimigas do Estado brasileiro.

Desse modo, a política criminal brasileira voltada aos crimes sexuais criada e alterada no período entre 2000 e 2015 revela, ao se aproximar do discurso político-criminal do inimigo, um pensamento abissal, com pretensões de universalidade, sem avaliar outras formas de controles sociais. Enfatizou a linha abissal que separa o cidadão daquele que se quer combater.

\section{REFERÊNCIAS}

ARAÚJO, Sara. Desafiando a colonialidade: a ecologia de justiças como instrumento da descolonização jurídica. Revista Latino-americana de Direitos Humanos, vol. 6, n. 01, 2015, p. 26-46, in http://www.periodicos.ufpa.br/index.php/hendu/article/viewArticle/2460. Acesso em 11/02/2016.

BRASIL. Lei ordinária 8072 de 25 de julho de 1990. Diário Oficial da União, Brasília, DF, 26 jul. 1990. Disponível em: http://www.planalto.gov.br/ccivil_03/leis/L8072.htm. Acesso em 04 jan. 2016.

BRASIL. Lei ordinária 10224 de 15 de maio de 2001. Diário Oficial da União, Brasília, DF, 16 mai. 2001. Disponível em: http://www.planalto.gov.br/ccivil_03/leis/LEIS_2001/L10224.htm. Acesso em 04 jan. 2016.

BRASIL. Lei ordinária 11106 de 28 de março de 2005. Diário Oficial da União, Brasília, DF, 29 mar. 2005. Disponível em: http://www.planalto.gov.br/ccivil_03/_ato2004-2006/2005/lei/111106.htm. Acesso em 04 jan. 2016.

BRASIL. Lei ordinária 11464 de 28 de março de 2007. Diário Oficial da União, Brasília, DF, 29 mar. 2007.2 Disponível em: http://www.planalto.gov.br/ccivil_03/_ato2007-2010/2007/Lei/L11464.htm. Acesso em 04 jan. 2016.

BRASIL. Lei ordinária 12015 de 07 de agosto de 2009. Diário Oficial da União, Brasília, DF, 10 ago. 2009. Disponível em: http://www.planalto.gov.br/ccivil_03/_ato2007-2010/2009/lei/112015.htm. Acesso em 04 jan. 2016. 
BRASIL. Lei ordinária 12654 de 28 de maio de 2012. Diário Oficial da União, Brasília, DF, 28 mai. 2012. Disponível em: http://www.planalto.gov.br/ccivil_03/_Ato2011-2014/2012/Lei/L12654.htm. Acesso em 04 jan. 2016.

BRASIL. Lei ordinária 12978 de 21 de maio de 2014. Diário Oficial da União, Brasília, DF, 22 mai. 2014.2 Disponível em: http://www.planalto.gov.br/ccivil_03/_ato2011-2014/2014/lei/112978.htm. Acesso em 04 jan. 2016.

BUSATO, Paulo César; MONTES HUAPAYA, Sandro. Introdução ao Direito Penal: fundamentos para um sistema penal democrático. $2^{a}$ ed. Rio de Janeiro: Lumen Juris, 2007.

Modernas Tendências de Controle Social. Revista Eletrônica de Ciências Jurídicas. Maranhão, n. 4, $2007 . \quad$ Disponível em: http://www2.mp.ma.gov.br/ampem/artigos/Artigos2007/ModernasTendencias-RECJ04.03-7.pdf Acesso em: 25 de fev. 2016.

Direito penal: parte geral. São Paulo: Editora Atlas, 2013. HOBBES, Thomas.

Leviatã. São Paulo: Martin Claret, 2007.

JAKOBS, Günther; CANCIO MELIÁ, Manuel. Direito Penal do Inimigo: noções e críticas. Org. e trad. André Luís Callegari e Nereu José Giacomolli. $2^{\mathrm{a}}$ ed. Porto Alegre: Livraria do Advogado, 2007.

. Derecho Penal: parte general, fundamentos y teoria de la imputación. $2^{\mathrm{a}}$ ed. Madrid: Marcial Pons, Ediciones Jurídicas, 1997.

MIR PUIG, Santiago. Estado, pena y delito. Buenos Aires/Montevideo: Julio César Faira Editor, 2006.

MORAES, Alexandre Rocha Almeida de. A Terceira Velocidade do Direito Penal: o direito penal do inimigo. 2006. Vol. 01. 327 fls. Dissertação. Programa de Mestrado em Direito da PUC-SP. São Paulo. 2006.

MUÑOZ CONDE, Francisco. De Nuevo sobre el Derecho penal del enemigo. $1^{\mathrm{a}}$ ed. Buenos Aires: Hammurabi, 2005.

QUINTERO OLIVARES, Gonzalo; MORALES PRATS, Fermín; PRATS CANUT, Miguel.

Curso de Derecho Penal: parte general. Barcelona: Cedecs Editorial, 1997.

SANTOS, Boaventura de Sousa. Para Além do Pensamento Abissal: das linhas globais a

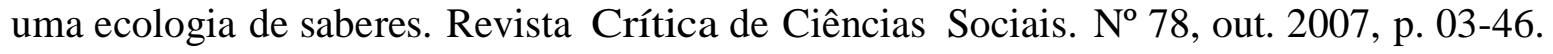

. Para uma Sociologia das Ausências e uma Sociologia das Emergências. Revista 
Crítica de Ciências Sociais. No 63, out. 2002, p. 237-280.

Introducción: las epistemologías del sur. Transcripción de la ponencia: Jesús Gutiérrez Amaparán y Natalia Biffi. Revisión del texto y redacción final: Bet Mañé. Formas- Otras. Saber, nombrar, narrar, hacer. Barcelona: CIDOB Ediciones, 2011, 9-22.

Para uma sociologia das ausências e uma sociologia das emergências. In Conhecimento Prudente para uma Vida Decente: um discurso sobre as ciências revisitado. São Paulo: Cortez, 2004.

WALLERSTEIN, Inmanuel. As estruturas do conhecimento ou quantas formas temos nós e conhecer? In Conhecimento Prudente para uma Vida Decente: um discurso sobre as ciências revisitado. São Paulo: Cortez, 2004. 